\title{
A Review of Recent Advances in Research on Extreme Heat Events
}

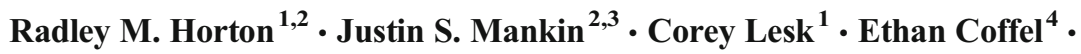 \\ Colin Raymond ${ }^{4}$
}

Published online: 3 August 2016

(C) The Author(s) 2016. This article is published with open access at Springerlink.com

\begin{abstract}
Reviewing recent literature, we report that changes in extreme heat event characteristics such as magnitude, frequency, and duration are highly sensitive to changes in mean global-scale warming. Numerous studies have detected significant changes in the observed occurrence of extreme heat events, irrespective of how such events are defined. Further, a number of these studies have attributed present-day changes in the risk of individual heat events and the documented global-scale increase in such events to anthropogenic-driven warming. Advances in process-based studies of heat events have focused on the proximate land-atmosphere interactions through soil moisture anomalies, and changes in occurrence of the underlying atmospheric circulation associated with heat events in the midlatitudes. While evidence for a number of hypotheses remains limited, climate change nevertheless points to tail risks of possible changes in heat extremes that could exceed estimates generated from model outputs of mean temperature. We also explore risks associated with compound extreme events and nonlinear impacts associated with extreme heat.
\end{abstract}

This article is part of the Topical Collection on Extreme Events

Radley M. Horton

rh142@columbia.edu

1 Center for Climate Systems Research, Columbia University, New York, NY 10025, USA

2 NASA Goddard Institute for Space Studies, New York, NY, USA

3 Lamont-Doherty Earth Observatory, Columbia University, Palisades, NY, USA

4 Department of Earth and Environmental Sciences, Columbia University, New York, NY, USA
Keywords Heatwaves $\cdot$ Extreme heat $\cdot$ Summer heat $\cdot$ Heat events

\section{Introduction}

The early years of the twenty-first century have seen numerous extreme heatwaves producing large societal impacts. Examples include 2003 in Europe, 2010 in Russia, 2015 in South Asia and the Middle East, and 2016 in Southeast Asia. These events are estimated to have collectively caused some 100,000 excess deaths [1-3], and were associated with a range of other human and ecosystem impacts, including wildfires [2], crop failures [4], and infrastructure disruption and damage [1]. Recent years have also seen important advances in scientific understanding of the dynamics, statistics, and impacts of extreme heat events. This review highlights developments from the last three years, which include (1) the burgeoning field of extreme event attribution, (2) new hypotheses about how wave-mean flow interactions may amplify heat events, and (3) the importance of considering heat in a broader context that includes interaction with other meteorological quantities beyond temperature (such as humidity), as well as spatial and temporal correlation of heat events.

The second section covers heat event definitions, highlighting the challenges posed by stakeholder-driven needs for geographic- and sector-specific, decision-relevant definitions on the one hand, and the need for science-based, standardized, and physically meaningful definitions on the other. The third section highlights recent advances in understanding the physical mechanisms underpinning heat events and how such mechanisms might change with warming. The fourth section reviews historical trends in high temperatures and heat waves. The fifth section assesses heat event detection and attribution to present-day anthropogenic warming. The sixth section 
summarizes projections of extreme high temperatures and heat waves. The seventh section focuses on compound or correlated events that involve extreme heat, and the eighth section describes emerging findings about extreme heat impacts. Despite much recent progress, key questions remain unanswered. The last section points to fertile areas for further research.

\section{Definitions}

There are many ways to define a heat event, and what constitutes one can vary considerably depending on the meteorological variables or impacts of interest (see [5] for a comprehensive review of heat event definitions). Temperature is often the only quantity used in heat event definitions due to its nearubiquitous measurement; moisture is rarely incorporated despite its strong correlation with thermal stress in humans and other large mammals (e.g., [6]). While three heat event metrics - magnitude, duration, and frequency - are of general importance, the myriad ways to define heat events imply that there are no simple answers to definitional questions about event thresholds ("what magnitude temperature anomaly is required?") or scope ("over what spatial and temporal scales?"). Definitions that consider only event magnitude or duration sacrifice critical information provided by the other [7]; combined approaches, such as "peaks-over-threshold," have been developed to address this [8]. Spatially, heat events have been defined on scales from the neighborhood [9] to the near-continental [10].

Another major distinction concerns definitions based on absolute temperatures versus percentiles. Absolute temperatures (and anomalies from a mean) are of central importance for many societal and environmental impacts, such as the biophysical heat tolerances of mammals or the resilience of infrastructure. Percentiles relative to the local climatology facilitate comparisons across locations and over time given differences in tolerance and preparedness (e.g., [11]), and when model and observational climatologies differ. However, percentile-based analyses sacrifice the physical intuition of actual temperatures. Recent emphasis on climate-risk management [12] and decision-oriented approaches has necessarily expanded the number of heat event indices used in research [13, 14].

Such a multitude of definitions points to a need for more work on creating a standardized set, foremost to facilitate interstudy comparison and to increase sample sizes of uppertail temperature events given large natural variability. Under the aegis of the World Climate Research Programme, an extremes standardization for observations and reanalysis is underway, motivated by the strict requirements of detection and attribution. The Expert Team on Climate Change Detection and Indices (ETCCDI) ${ }^{1}$ has defined 27 internationally-agreed indices of climate extremes based on daily data, facilitating the synthesis of regional analyses of changes in climate extremes. A number of datasets of such indices are now available at the gridded-global scale, where station data support interpolation.

At the same time that standardization facilitates detection of climate signals in heat extremes, definitions (like models) are best chosen based on the problem at hand. As climate service-based approaches expand, it seems inevitable that the number of definitions will grow in proportion to the number of sector-based decisions studied in regional contexts. In defense of the notion that it would be inappropriate to iron out all definitional diversity in the name of standardization, we include heat events ranging from a single day to the monthly scale (however, warm anomalies during cold seasons are outside our scope). Such definitional diversity is in part a reflection of the myriad physical mechanisms proposed as the proximate and underlying drivers of high-heat events.

\section{Mechanisms Underpinning Heat Events}

It is now well understood that relatively modest amounts of global mean warming associated with anthropogenic climate change can produce large changes in local heat event characteristics such as frequency, intensity, and duration $[15,16]$. In contrast, the topic of physical mechanisms behind extreme heat events, and how these mechanisms may change with climate change, is an emergent area of research, with much evidence still required [16-25]. Diagnosis of heat event mechanisms is critical to understanding the potential for nonlinear responses in extreme heat beyond those expected from global mean warming alone.

For organizational purposes, this section separately presents (1) the proximate drivers and land-atmosphere feedbacks in heat events and (2) the underlying extratropical anticyclonic circulations, blocking events, and jet-stream excursions that are more generally associated with extreme summer heat. In the final two subsections, we present a discussion of how anthropogenic forcing may alter/have altered these heat event dynamics with a review of (3) hypothesized midlatitude planetary wave mechanisms that attempt to account for heat extremes and extreme weather more generally and (4) other influences that may alter proximate and underlying drivers of heat events. In practice, however, there is considerable overlap among all these mechanisms, rendering causative statements illusive given nonlinear dynamics and incompletely characterized physics.

\footnotetext{
${ }^{1}$ http://www.wcrp-climate.org/unifying-themes/unifying-themesobservations/data-etccdi
} 


\section{Proximate Drivers and Land-Atmosphere Feedbacks of Heat Events}

From an atmospheric perspective, heat events tend to feature the following: (1) subsidence of air (high surface pressure) and the associated warming and drying of air from adiabatic compression; (2) clear skies, which support warming (latent and/or sensible heat fluxes) during the high-insolation summer; and/ or (3) advection of warm air. In many locations, the last will preferentially be a poleward wind, but there are two common exceptions: the peripheries of large continents, where a daytime wind from the interior will often be warmer than a wind of maritime origin, and regions near higher mountains (such locations can experience their highest temperatures when dry mountain winds descend, compress, and warm the valleys) $[26,27]$. Much of coastal California for example, where an easterly wind generally is associated with heat events $[26,28]$, meets both these criteria.

Heat events can be viewed through the lens of landatmosphere interactions as well. Anomalously low soil moisture conditions are associated with heat, since energy from insolation is preferentially partitioned to sensible - rather than latent-heating. Temperatures during the European heatwaves of 2003 and 2010, for example, were found to be significantly amplified by soil moisture deficits in a positive feedback loop: As temperatures rise, soil moisture declines reduce latent heat flux, allowing temperatures to rise further [29-32]. This feedback is especially present in semi-arid regions, and can be either amplified or diminished by human land-use practices, such as irrigation [33]. Land-atmosphere feedbacks can play a critical role in determining the onset of heatwaves, particularly in the extratropics, when larger scale circulation situates persistent anticyclones over regions, as discussed below.

\section{Underlying Drivers: Extratropical Anticyclones, Blocking, and Heat Events}

Extratropical heat events can be more broadly contextualized by considering the larger scale atmospheric dynamics that favor the thermodynamic processes and land-atmosphere feedbacks discussed above. Transient anticyclones (sometimes accompanied by a low-level thermal low) support high insolation associated with clear skies, adiabatic warming of air as it sinks, and poleward advection of warm air along the western flank [28]. When these anticyclones are slow moving or stationary, they are often referred to as "blocks," since they alter the jet stream's climatological path and hinder the progression of synoptic weather systems [34, 35]. Blocking anticyclones are difficult to measure quantitatively, but they can drastically decrease weather variability at synoptic timescales, allowing heatwaves the time to build $[19,34,36]$. These conditions can be influenced by myriad factors, including enhanced or diminished convection in the tropical Pacific (e.g., [37] and references therein). While there has been documentation of more anticyclones in some midlatitude regions in recent decades [38,39], there is no discernible hemispheric trend in summertime atmospheric blocking events [19]. Additionally, observational evidence for either increased anticyclones or blocking events generally covers too short a time period to detect a signal amidst the noise. Furthermore, even when signals in circulation anomalies are robustly detected, linking them to global warming can represent an additional hurdle.

Consider, for example, two conflicting influences of global warming on blocking: Dry dynamic theory tends to account for much of the physical intuition behind atmospheric blocking events; however, Pfahl et al. [35] identify a tendency for summer blocks to be preceded by strong upstream heating associated with rising air in storms. This suggests that warming could lead to more diabatic heating within moister air, bringing stronger blocks thereafter [35]. However, Hoskins and Woollings [40] hypothesize that because blocking is favored downstream from storm tracks (e.g., [41]), and a weakening equator-to-pole temperature gradient can mean weaker storm tracks [23], downstream blocking could decrease in a future climate [42]. CMIP3 and CMIP5 models generally project fewer blocking events in the future, although Hoskins and Woolings note that midlatitude blocking could change due to a feature not captured by general circulation models (GCMs), such as changes in tropical forcing [40]. It remains that the theoretical basis for future changes in blocking variability is not established and the scientific debate surrounding blocking is emblematic of debates about future changes in midlatitude circulation more generally.

Irrespective of the fact that the physical drivers and observational measures of blocking events are still being refined and the theoretical basis for their future change is unknown, midlatitude circulation anomalies do share a common trait of being excursions of the extratropical jet from its climatology [18]. In the midlatitudes, Rossby (or planetary) waves manifest as north-south meanders in the jet stream associated with pressure ridges (characterized by warm poleward winds) and troughs (characterized by cold equatorward winds) across the hemisphere. Rossby waves propagate westward relative to the mean flow and, in doing so, redistribute energy and momentum in the atmosphere across a spectrum of wavelengths (or wavenumbers) and phase speeds. Standing (or quasistationary) Rossby waves are principally forced by differential meridional and zonal heating of the planet arising from factors like topography and the distribution of continents and oceans. In contrast, transient fast-moving (or free) Rossby waves arise from a variety of energy sources, such as variability in deep tropical convection associated with high sea-surface temperatures (SSTs) and variability in other eddy-driven phenomena. In the present-day climate, the complex interaction of free and 
standing Rossby waves and mean flow features such as the jet stream can force the persistent anticyclonic anomalies associated with midlatitude heat extremes.

\section{Planetary Wave Forcing of Persistent Boreal Summer Heat Events?}

A critical and outstanding question is whether the mechanisms driving boreal summer circulations have changed or will change in a forced climate, causing a nonlinear response in high-heat events. Because we are focused on warm-season heat events, we briefly discuss the debate around two recent and related mechanisms that are purported to reflect anthropogenically forced changes in boreal summer wave-mean flow interactions, based (contentiously $[40,43]$ ) more on the role of Arctic warming than tropical forcing. The two hypothetical mechanisms are (1) increased amplification of standing and short wavelength Rossby waves (called "quasi-resonant" circulation regimes) and (2) weakening of fast-moving Rossby waves and associated storms. Note that the two mechanisms are active areas of research, and as such their theoretical basis in either the observed or future climate is not established. However, the two hypotheses would be consistent with nonlinear increases in extreme heat events. Furthermore, the hypotheses complement one another as both account for reduced summer weather variability at synoptic time scales, and there is some evidence that both are occurring in boreal summer [21].

\section{"Resonant" Circulation Regimes}

Planetary wave influence on midlatitude weather in all seasons is a topic of active research. In the boreal midlatitude summer, amplifying interactions among standing (quasistationary) Rossby waves and fast-moving (free) Rossby waves of similar wavenumber (e.g., 6-8) have been proposed as being critical in producing long-standing heatwaves and other extreme events [17, 18, 20, 21, 23, 37, 44]. This "quasi-resonance" of Rossby waves is associated with a double jet stream that traps Rossby waves within a latitudinal band, or waveguide $[17,21,45]$. Such resonance creates highly persistent amplifications of the standing summertime ridge-trough (and associated meridional wind) pattern across the boreal hemisphere, decreasing summer weather variability during the period of resonance (Fig. 1). These resonance regimes comprise a special form of long-standing, hemispheric-scale atmospheric blocking events, which favor monthly anomalies like the 2003 European, 2010 Russian, and 2011 North American heatwaves [17, 21, 23] (Fig. 1).

While rare, the boreal summer quasi-resonance phenomenon and associated double jet stream described above has become more likely in the last decade or so, which the authors claim intimates at the culpability of global warming $[17,21]$.
However, the record is short (32 years) and the speculative link requires much further testing based on both observations and additional idealized model experiments [18]. Beyond an incipient theoretical basis for quasi-resonance and its link to heat extremes, some observational evidence for it exists [21]; however, the evidence remains mixed, and its detection is potentially sensitive to how quasi-resonance is measured $[43,46]$. Thus, considerable scientific work remains to establish anything more than an associative link to changes in heat extremes.

\section{Weakened Zonal Winds and Summer Storms}

Increases in midlatitude extreme heat events have also been loosely attributed to weaker zonal flow [21] and reduced summer storms [21,23-25]. The proposed mechanism is that transient fast-moving waves slow and weaken in response to a weakened equator-to-pole temperature gradient from Arctic amplification [21, 23-25, 47], which reduces baroclinicity [25, 43]. Coumou et al. [23] report that a combination of weaker waves with slower phase speeds has reduced eddy kinetic energy (EKE, a quantity of transient systems) by a striking two standard deviations, a departure climate models do not project under large radiative forcing until approximately 2100. Lehmann and Coumou [24] also report observed and projected decreases in summer storm tracks across the midlatitudes, finding that more than three fourths of the land area between 35 and $65 \mathrm{~N}$ has seen decreases in EKE in summer. The reduced EKE (and by extension reduced rain, clouds, and wind-induced mixing of air masses) would likely be associated with decreasing soil moisture, pointing to a potential landatmosphere feedback (discussed in the "Proximate Drivers and Land-Atmosphere Feedbacks of Heat Events" section) that could exacerbate and/or lengthen heat events [21, 23].

The future role of polar forcing relative to tropical forcing of midlatitude weather extremes has been and remains contentious (e.g., [19, 23, 43, 48-53]). What is well accepted is that models suggest that Arctic warming can influence the position and strength of the midlatitude jet and, thus, the position of persistent circulation regimes that give rise to heat events [43]. However, the direction of the jet's change remains ambiguous. Beyond the myriad factors that influence jet position and speed, there exists a countervailing response to global warming: the change in the temperature gradient in the lower troposphere (from Arctic amplification) is consistent with an equatorward shift of the jet, while the change in the upper-troposphere gradient is consistent with a poleward shift in the jet, establishing a potential "tug-of-war" in the jet's positional response to warming [43].

Much of the contention has focused on fall and winter (when recent sea ice anomalies and the baseline hemispheric meridional temperature gradient are largest, respectively). However, summer has three characteristics that buttress 


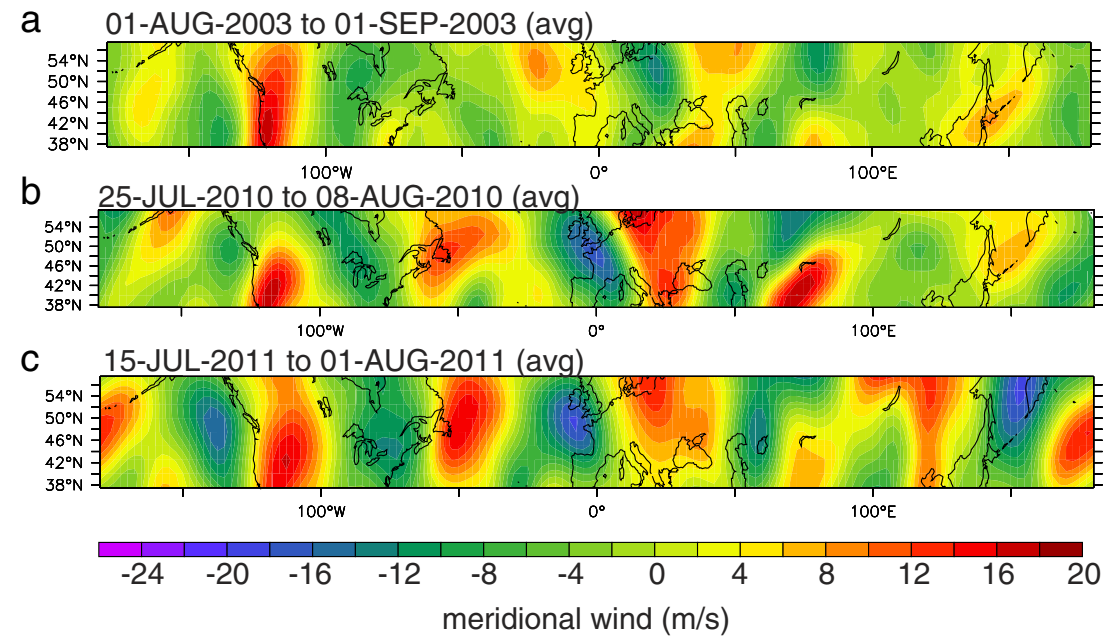

Fig. 1 Northern Hemisphere midlatitude meridional winds at $300 \mathrm{hPa}$ for three recent summer high heat events. a The record European summer heat wave in August 2003; b the most devastating phase of the Russian heat wave, July 25 to August 7, 2010; and $\mathbf{c}$ the most serious phase of the summer 2011 heatwave in the USA. The quasi-resonant patterns with a strong contribution from zonal wave numbers $m=6(\mathbf{b}, \mathbf{c})$ and $m=7$ (a) are clearly seen. From Petoukhov et al. [17], based on NCEP/NCAR reanalysis claims of links between Arctic amplification and midlatitude temperature extremes. First, summer is the season when the meridional temperature gradient in the high latitudes has decreased the most dramatically, in conjunction with the emergence (late relative to other seasons) around 2000 of Arctic amplification [21]. During this period, late spring/early summer snow cover has decreased dramatically in the high latitudes [53], near the time of year of maximum insolation. This reduced gradient has been generally concurrent with the aforementioned decreased zonal circulation and decreased EKE predicted by the hypothesis [23-25]. For example, Barnes and Polvani [51], looking at a western hemisphere domain, found that the correlation of Arctic amplification with both jet latitude and strength was strongest in summer. Second, it is thought that the midlatitudes are least sensitive to tropical forcing during the summer season; to the extent that the easterly winds of summer can limit the ability of tropical waves to move poleward, there may be more "room" for other factors such as Arctic amplification to influence the midlatitudes. Finally, lower variability in summer may ease detection of any dynamical signals predicted by the hypothesis. However, because other factors have not been conclusively ruled out nor the direction of causation explicitly tested [43], any estimate of reduced free Rossby waves (such as those measured by EKE) has not been attributed to the Arctic amplification that has occurred.

\section{Implications for Future Heat Events}

There are many caveats to these and other studies pointing to large changes in heat waves due to changing dynamics. Most fundamentally, even in summer, when natural variability is lowest, noise may mask signals (or make noise appear to be a signal). With respect to the Arctic-associated mechanisms described here, the period of record in which any purported forcing might be strong enough to be detectable is as short as approximately 10-15 years, depending on whether Arctic sea ice loss or Arctic amplification is emphasized.

Equally as vexing is the question of heat wave causation. While the dynamical configurations in recent summers appear conducive to more heat events through known processes, it does not necessarily follow that the heat events are due to the anomalous dynamics. More research is needed on the union between the dynamical extreme (such as quasi-resonance) and heat events, under various definitions. Do the recent heat extremes tend to recur in the same locations, and how do those locations correspond to the areas experiencing the extreme dynamics (such as blocking or anomalous EKE?) (Recall that Hoskins and Woolings [40] hypothesize that blocking high pressure would be expected to decrease downstream as storm tracks weakened). How well does persistence associated with the large-scale dynamical mechanisms explain heat wave evolution, relative to the predictions associated with existing, more localized, theories of heat wave evolution (e.g., Miralles et al.[32])? While only representing a single model and location, the analysis of Teng et al. [54] of projected heatwaves over the Great Plains is important because it partitioned both planetary wave and land surface factors, concluding that only the latter could explain projected increases in heat waves there.

The question of causation of any changes in midlatitude dynamics is even more challenging. Changes in the summer midlatitudes and Arctic may share a common mechanism, perhaps in the tropics (e.g., Ding et al. [55]). Petoukhov et al. [17] and Hoskins and Woolings [40] both emphasized 
that subtleties in the subtropical jet - which a priori are more driven by the tropics than the Arctic - are critical to quasiresonance. Midlatitude dynamical changes may have a hand in Arctic amplification, sea ice loss, and early snow retreat as well.

The combination of short observed record, high midlatitude variability, and range of potential causes all point to a need for more modeling experiments of varying complexity to estimate the potential for a nonlinear response of heat events to warming. Of course, the models may be missing physical processes key to heat event representation, biasing future estimates of heat events. For example, as Hoskins and Woolings note [40], model simulation of blocking has improved with higher resolution and new parameterizations [56], but model biases in the CMIP5 archive, such as too little blocking, remain $[57,58]$.

\section{The Outlook for Changes in Potential Drivers}

Beyond the potential for forced changes in the circulation regimes associated with boreal summer heat events discussed above, there are a number of other potentially related factors which could either directly or indirectly influence changes in heat event occurrence, magnitude, and duration from anthropogenic forcing. This subsection briefly explores how heat waves could be impacted by projected changes in four aspects of the climate system: land-atmosphere coupling, aerosols, differential warming of land and ocean, and tropical forcing. These four topics should not be considered comprehensive or fully independent; we briefly discuss their potential to influence heat events in the present and future.

\section{Land-Atmosphere Coupling}

Climate change will likely modify soil moisture [59] — and by extension, heat waves - through multiple mechanisms. The surface temperature response to land-atmosphere coupling is strongest where soil moisture is moderate; thus, there is some expectation that future summertime drying of the midlatitudes and subtropics will increase the responsiveness of surface temperature to the transient circulation anomalies [60-62], associated with heat events. A recent single model experiment found that higher carbon dioxide concentrations could reduce daytime water transfer through plant stomata, thereby increasing the warmest yearly maximum temperature by as much as $5{ }^{\circ} \mathrm{C}$ through this mechanism alone; this total far exceeds the projected increase in summer average daily maximum temperature [63]. Climate change has been linked to drier lower boundary conditions in the subtropics and midlatitudes through a variety of mechanisms, including reduced precipitation due to poleward expansion of the sinking branch of the Hadley cell [64], and greater potential evaporation as summer temperatures rise, potentially increasing aridity [65]. A shift in the distribution of precipitation toward a larger percent occurring in extreme events could also be associated with larger, more frequent, and longer duration negative soil moisture anomalies [66], potentially augmenting heat waves. Where summer soil moisture anomalies are correlated with winter and spring snowfall, rainfall, and evaporation, climate change impacts in antecedent seasons may offer another pathway to changes in heat events [67].

\section{Aerosols}

Reductions in aerosol emissions anticipated in the representative concentration pathways (RCPs) could increase heat extremes through multiple mechanisms, potentially at levels that rival or exceed the heatwaves averted under an RCP 4.5 as opposed to 8.5 scenario [68]. Direct radiative effects of aerosols generally decrease heat extremes by reducing incoming solar radiation, although this varies with aerosol type and distribution. Aerosol indirect effects can also influence cloud characteristics and precipitation, thereby affecting heat extremes through radiative fluxes and soil moisture [69]. Aerosols have also been modeled to modulate heat waves through dynamical mechanisms [54]. For example, Xu et al. [68] project reduced duration of tropical heat waves, because aerosol cooling results in an equatorward shift of the Hadley cell edge, and thus more frequent intrusions of midlatitude air and a decrease in periods of extended stagnation.

\section{Differential Warming of Land and Ocean}

Climate change is in general expected to warm land more than ocean, which could impact heat waves in multiple ways. Model experiments have confirmed the intuition that increasing summer temperature gradients due to differential land and ocean warming can be an important source of increased summer temperature variability, locally rivaling or exceeding the individual impacts of any changes in circulation or land surface/radiative fluxes [70, 71]. Shaw and Voigt [72] propose that differential land versus ocean warming is one possible explanation for an observed and modeled amplification of subtropical stationary waves in summer - a likely driver for more extreme temperatures. However, they caution that the larger amplitude subtropical stationary waves could be due to other factors besides differential warming, such as wavemean flow interactions with an anthropogenically strengthened subtropical jet [72].

Differential warming of land and ocean may indirectly impact heat waves by changing the timing and intensity of monsoons; in many regions, the arrival of the monsoon-with its cloud cover and moisture induced cooling - brings an end to the hottest period of the year, especially as defined by daytime highs. The IPCC Fifth Assessment Report concluded that, globally, monsoon precipitation was likely to increase this 
century, with increases in monsoon precipitation extremes very likely in several regions [73].

\section{Tropical Forcing}

Recent studies have challenged the conventional view that Rossby waves of tropical origin only minimally impact summer midlatitude temperature anomalies (due to weaker tropical modes like ENSO and the inability of Rossby waves to propagate through the easterly wind regimes common in summer) [20, 37]. Other studies (e.g., Ding et al. [55]) have demonstrated that tropical SST anomalies may warm the Arctic, which could in turn impact the midlatitudes, as described in the section "Planetary Wave Forcing of Persistent Boreal Summer Heat Events?." While there are large uncertainties about how tropical forcing may change in the future, growing understanding of links to midlatitude heat waves, and even potential predictability of midlatitude heat waves anywhere from approximately 2 weeks [20] to as much as 7 weeks in advance [74], argues for further study.

In summary, the evidence is strong that mean warming, including higher sea-surface temperatures, will lead to more frequent and intense heat waves [75]. Thermodynamic physical arguments and model projections also point to increases in monthly scale summer temperature anomalies in much of the midlatitudes, consistent with lower soil moisture and increased land-sea temperature contrast [70]. Many of the dynamic links described in this section are by contrast less well established. While uncertainty bounds are large, from a risk perspective, the large potential consequences of heat extremes (see "Impacts" section) suggest a need for more research. Key topics include implications of any rapid changes in the climate system that exceed GCM projections - such as Arctic sea ice loss in the high latitudes - for heat wave frequency and duration through complex wave-mean flow interactions. A less controversial topic, observed changes in extreme heat, is the subject of the next section.

\section{Historical Analysis and Trends}

Because extreme heat events are by definition rare, it can be challenging to identify statistically significant trends, relationships to modes of natural variability, and preindustrial period recurrence intervals for various heat thresholds [76]. The possibility of forced changes in variability over the observational record poses an additional challenge to statistical characterization of extreme heat events $[8,76]$. Perkins [5] provides a summary of links between heat events and modes of natural variability.

The above challenges require high-quality, long duration observational records of high temporal and spatial resolution, which are unavailable for much of the world. The HadEX2, the most comprehensive station-data-derived gridded dataset of temperature and precipitation indices, for example, meets the $>90 \%$ temporal coverage standard for temperature only from 30 to $70 \mathrm{~N}$ and $30 \mathrm{~S}$ to $45 \mathrm{~S}$ and from approximately 1955 onwards, leaving out much of the rest of the globe as well as earlier time periods [77]. Despite these caveats, much has been learned in recent years about observed heat extremes (see [78] for a global review) from single-day to more persistent or multiday events.

The Fifth Assessment Report of the IPCC concluded that anthropogenic emissions have very likely contributed to the global-scale increases in daily-scale temperature extremes since 1950 and likely doubled the probability of heatwave occurrence in some locations [73]. Since that assessment, there has been a documented increase in the number of heat events across regions in the last several decades beyond what would be expected in a stationary climate [77-86].

A recent study showed that global mean warming $\left(\sim 0.85^{\circ} \mathrm{C}\right)$ has been sufficient to account for $\sim 75 \%$ of "moderate daily hot extremes" over land, globally (Fig. 2a) [39]. In an analysis of 217 urban areas globally, between 1973 and 2012 , there has been a significant increase in extreme hot days in $50 \%$ of cities and extreme hot nights in $65 \%$ of cities [81]. The only region with decreases in extreme hot days was East Asia [81]. The same study found that 4 of the 5 years with the most heatwaves globally occurred during the last 4 years of their 1973-2012 analysis period. In an observational study focused on the more recent post-1997 period, Seneviratne et al. note that daily high temperature extremes over land have continued to warm steadily during a period of slower global mean temperature increase [85]. They largely attribute the relative lagging of global mean temperature increases to cooling concentrated over the oceans and over land in the cold season, but also note that even over land areas in summer, there is evidence that extremes are warming faster than the mean, though this conclusion remains preliminary. The observed increase in heat waves and other extreme events has fostered rapid advances in extreme event attribution, the subject of the next section.

\section{Attribution of Recent Events}

Recent years have seen an increase in analyses attempting to attribute extreme climate events - including heat events - to anthropogenic warming. Because extreme events are rare [87], attribution of any given event to anthropogenic climate change is an analytical challenge, particularly given both high- and low-frequency modes of internal climate variability $[75,88,89]$, and their interaction with expected forced trends. There are two primary attribution approaches, discussed below: (1) an "attributable risk" framework and (2) a synoptic environment, or "ingredients-based," framework [75, 90]. 


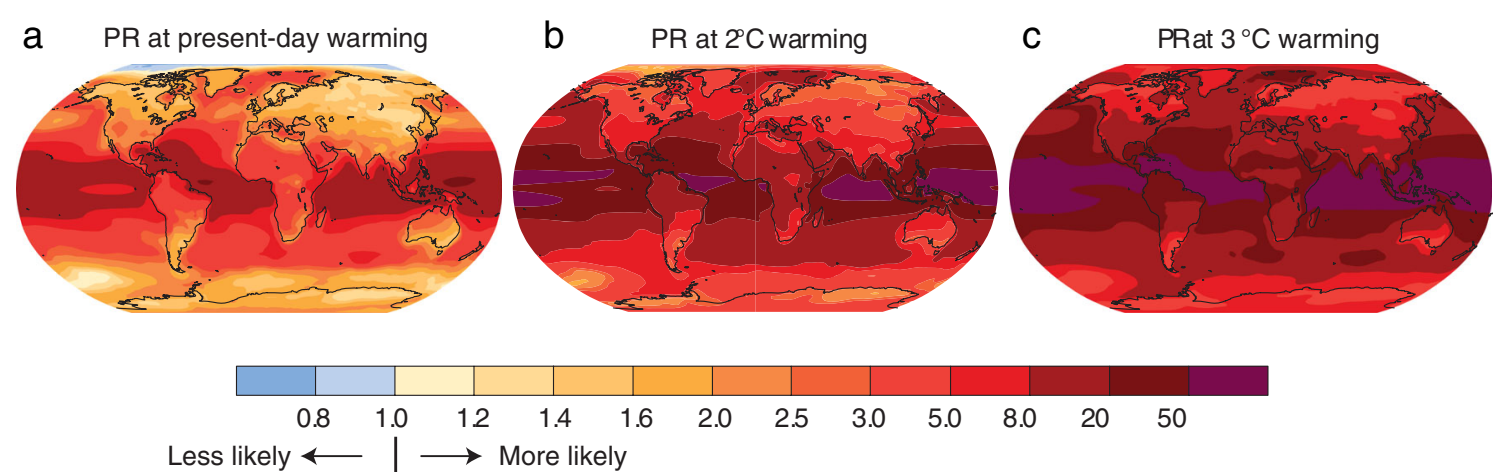

Fig. 2 Change in the probability of hot extremes in the present and future. The 25 member CMIP5 multimodel mean probability of exceeding the preindustrial 99th percentile temperature, in the presentday $(\mathbf{a})$, at $2{ }^{\circ} \mathrm{C}(\mathbf{b})$, and $3{ }^{\circ} \mathrm{C}$ (c) global mean temperature. These are

Both require precise detection of the event to place it in proper distributional context [91, 92], but their differences reflect divergent philosophies about appropriate usage of statistics and models, and about the nature of causation. Heat events, which are robustly linked to thermodynamics, are on the whole easier to attribute to anthropogenic forcing than are purely dynamical changes like circulation anomalies - insofar as the latter are even detectable [75].

The requirements of a traditional approach to attribution are strict: the identification of an external cause or set of causes, exclusive to all others, without which the event in question would not have occurred [93]. This is a challenging standard to meet because of earth-system complexity, statistical limitations, and our imperfect knowledge of the oceanatmosphere state at any one moment. Mechanistically, it rests on applying parametric statistics to observations and model simulations with and without observed anthropogenic forcing. However, the challenge is that the traditional approach to attribution is intractable for any single heat event. It can be used, however, on climatologies of heat events or indices (e.g., [94]).

\section{Attributable Risk}

The first approach to address this shortcoming leverages an attributable risk framework: Rather than asking "was event A caused by climate change?," it asks: "Has anthropogenic climate change altered the probability of event $A$ 's occurrence, its magnitude, or its duration?" $[78,89,92,95,96]$. Calling the answer to this second question "attribution" requires a nuanced understanding of causation. Change in an event's attributable risk [88] (often quantified as a probability ratio [39], or one minus its inverse, called the fraction of attributable risk, FARS $[5,39,92,95,97,98])$, does not mean in this framework that the exact same event could not have occurred in a preindustrial climate. presented as the ratio of the 30 -year probability in each time period relative to the pre-industrial. Some $75 \%$ of 99 th percentile hot extremes are already attributable to the warming that has occurred (a). From Fischer and Knutti [39]

\section{Ingredients-Based Attribution}

The second approach to extreme event attribution examines the proximate synoptic environment (e.g., SSTs, jet streams) within which the event developed $[24,28,38,75,99]$. The method then uses a fingerprinting approach to identify whether the warming that has occurred has altered the likelihood of that particular synoptic pattern. Partitioning out the dynamic and thermodynamic contributions to the pattern, with the latter serving as a proxy for mean global warming [38, 75], allows for attribution of the forcing to anthropogenic causes if the dynamics are well understood.

\section{Summary of Heat Event Attribution}

Yet despite shifting the goalposts of what constitutes the identification problem, many challenges of heat event attribution remain, from definitional questions $[5,100,101]$ to the best metric (frequency, magnitude, duration) to consider [80, 102, 103]. Beyond the IPCC's assessment of a doubling of heatwave occurrence likely attributable to global warming, fingerprinting approaches have been applied to the statistics of observed temperature extremes, finding anthropogenic causes as culpable $[104,105]$. On the single-event attribution front, for the last 4 years, the Bulletin of the American Meteorological Society has published an event attribution issue on a selection of each year's extreme events $[92,95]$. Of the 22 heat events examined, 21 identified anthropogenic warming either as the primary culprit or as having materially altered the chance of the event [92]. The question of whether anthropogenic forcing has caused a global-scale increase in temperature variability - and thus whether there are additional heat events than would occur from just a shift in the meanremains unsettled $[16,100,101,106]$. However, there is emerging evidence for this hypothesis [107-109] which could arise from the mechanisms described in the section "Mechanisms Underpinning Heat Events." As described in 
the next section, GCM temperature outputs, which are presumed to at least partially capture some but not all of these mechanisms, also point to large future changes in extreme heat events.

\section{Projections}

An extensive literature covers climate model projections of high-temperature extremes under the different RCPs or forcing scenarios [78]. Projected changes in heat event (1) magnitude, and (2) recurrence and time of emergence are summarized below.

\section{Projected Changes in Heat Event Magnitude}

Climate change is very likely to cause a continued increase in the frequency, magnitude, and duration of heat events [73], and for many regions, there is evidence that the most extreme hot temperatures may warm faster than the seasonal mean (e.g., $[110,111])$. Using 19 CMIP5 models, Sillmann et al. [112] report that changes in the seasonal and annual maximum daily maximum temperature (TXx) have a relatively weak equator-to-pole gradient (in contrast to minimum daily minimum temperature (TNn), which is projected to warm most at high latitudes, and at a rate exceeding TXx). They note a tendency for the largest projected TXx warming to occur in continental interiors, possibly linked to projected soil moisture anomalies. They also report that in the northern mid and high latitudes, TXx is projected to warm more in summer than winter, with the Mediterranean standing out as a region where summer warming of TXx (in association with a strong drying signal) is so large as to provide an exception to the general expectation that winter warming rates of cold extremes will exceed summer warming rates of warm extremes.

\section{Projected Changes in Heat Event Recurrence and Time of Emergence}

Extreme temperature projections are increasingly being expressed using decision-relevant metrics that go beyond temperature changes. Two of the most prominent examples are (1) changes in recurrence intervals/frequency and (2) time of emergence (TOE), which describes when a particular climate change signal has, or is projected to, separate from natural variability [113].

In a combined historical and projection analysis of global extremes, Fischer and Knutti [39] found that already (with $0.85{ }^{\circ} \mathrm{C}$ of warming globally) the preindustrial 1-in-1000day extreme heat event has become roughly five times more likely. They also project that a $2{ }^{\circ} \mathrm{C}$ warming approximately doubles the risk of heat extremes relative to $1.5^{\circ} \mathrm{C}$ warming, yielding an additional fivefold increase in frequency relative to the present climate; panels $\mathrm{b}$ and $\mathrm{c}$ of Fig. 2 respectively show the change in the probability of extreme heat associated with 2 and $3{ }^{\circ} \mathrm{C}$ warming, relative to the preindustrial period [39]. The corresponding frequency changes for extended heat events are projected to be larger still, as the baseline distribution for extended duration events is narrower than for singleday extremes.

Regional studies of heat extremes have also demonstrated how strongly low baseline variability - as is found in the tropics and to a lesser extent the subtropics - influences frequency of occurrence and time of emergence, with tropical regions such as northern Australia and much of Africa [114] projected to see large increases despite only moderate amounts of absolute warming $[112,115]$. On a percentile basis relative to the current climatology, Russo et al. [13] project that by 2100 , under the RCP 8.5 pathway, events as anomalous locally as the Russia 2010 heatwave was will occur as frequently as every year in much of the tropics and the drier parts of the midlatitudes. But the climate change signal is not limited to low variability regions like the tropics: using $27 \mathrm{GCMs}$, Bador et al. [116] report that as soon as 2030 European heat extremes may emerge from what was experienced in a 1900-2005 model baseline. Further, King et al. [117] find that over much of the globe a climate change signal is already detectable in onceper-year temperature extremes.

The use of time of emergence in extremes research is expanding rapidly, due in part to intuitiveness and decisionmaker relevance. However, cross-study comparisons are challenging since the ToE results are so sensitive - often spanning from the past to the future - to how time of emergence is defined, as well as the base period and spatial area analyzed. The next section describes another active area of extremes research: changes in compound events.

\section{Compound Events}

Many of the extremes that most impact society cannot be captured by a single climate variable at a single location and time. A focus on climate impacts and stakeholder engagement steers extreme event analysis toward (1) consideration of multiple climate variables simultaneously, and (2) temporal and spatial relationships between extremes of the same and different types. From a risk management perspective, positive correlations - whether across climate variables, in space and time, or across drivers of extremes and their impacts - may lead to tail risks in excess of what would be estimated based on the distribution of a single variable in isolation [118].

\section{Multiple Variables}

When considering human health impacts, it is essential to consider humidity as well as temperature because the human 
body cools itself via evaporation. When the wet-bulb temperature (the lowest temperature possible to achieve through evaporative cooling alone) exceeds the skin temperature, the body cannot cool itself. This wet-bulb temperature threshold under ideal conditions of shade, perfect health, and the absence of physical exertion is about $35{ }^{\circ} \mathrm{C}$; above this, heat illness and eventually death will occur without artificial cooling [119]. Recent research has focused on the severe impacts of heat-stress events on human health and economic activity [120], events which may exceed the limits of human tolerance in some areas during this century [121]. Other large mammals face similar risks [122, 123].

Temperature and relative humidity are thermodynamically related, and as a result, the uncertainties regarding joint temperature-humidity variables are smaller than would be expected if each variable were taken independently [124]. Due to this relationship, the climate models with the largest increases in temperature tend to feature large decreases in relative humidity. This effect decreases the intermodel spread of joint heat-stress variables, such as the wet-bulb temperature. Nevertheless, as shown in Fig. 3, the current once per year extreme wet-bulb temperature is projected under RCP 8.5 to occur one to two orders of magnitude more frequently by the 2060s in many regions, representing a larger increase in frequency than is expected for temperature alone. Pal and Eltahir's [121] high-resolution modeling of the risk in the Middle East could provide a template for the types of assessments needed to identify the highest risks globally, which are likely to occur in or near regions with high SST, low elevation, and possibly interaction between humid coastal air masses and hot interior ones.

Relatively few assessments have been made of joint risk of extreme heat and drought [125], despite their thermodynamic link through soil moisture anomalies. Trenberth and Shea [126] identified a negative correlation throughout the subtropical and midlatitude summer hemisphere land masses between monthly temperature and precipitation anomalies. Mazdiyasni and AghaKouchak [127] report that over the southern and western USA, risk of concurrent severe drought and heatwaves has increased dramatically, even though no statistically significant trends in drought risk alone can be detected. Correlations with other variables, some of which may partially reflect heat impacts, should also be explored. Extreme heat events have been correlated with poor air quality, high solar radiation, low winds, forest fires, and heightened risk of power failures due to increased power demand and reduced cooling water availability for power plants [124].

\section{Temporal and Spatial Correlation}

Temporal and spatial correlation of heat events with both heat events and other types of extremes is another emerging research area. As an example of temporal correlation, in many midlatitude regions, tropical cyclone season ramps up in late summer, around the time heat risk is beginning to wane. If warming of the upper oceans were to support an earlier onset to the tropical cyclone season $[128,129]$, risk of extreme heat events (at a time of higher insolation) near in time to a tropical cyclone landfall could increase as well. In terms of spatial correlation, Trenberth and Fasullo [130] argued that the 2010 Russian heat event was part of a larger pattern of anomalous global extremes that included flooding in Pakistan and in northern parts of South America and Australia. Any dynamical or thermodynamic changes of the types described in the section "Mechanisms Underpinning Heat Events" that increase the risk of concurrent extreme heat events, possibly in
Fig. 3 Multimodel mean annual maximum air temperature in the period 1985-2004 from ten selected CMIP5 models; $\mathbf{b}$ same as a for wet-bulb temperature from the same set of models; c mean number of days per year in 2050-2069 which exceed the mean annual maximum temperature shown in $\mathbf{a}$; $\mathbf{d}$ same as $\mathbf{c}$ but for wet-bulb temperature
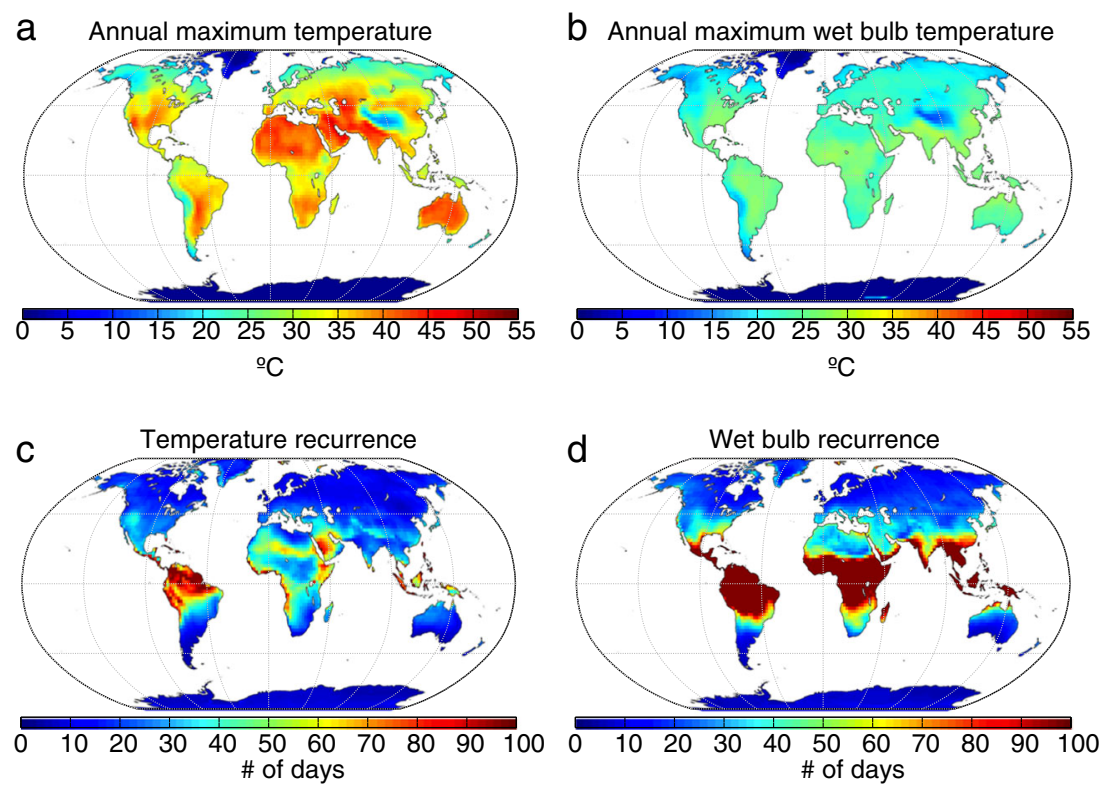
combination with other extremes (e.g., flooding $[17,131]$ ), could have large implications for sectors ranging from reinsurance to food availability and cost.

Although in its infancy, the study of compound events offers high potential for advances of societal relevance. More frequent heat events (and other types of extremes) are expected to yield more compound events due to chance alone. But more research is needed on how large this simple statistical effect might be, relative to the wildcard of correlated extremes due to a shared physical process such as changes in planetary waves. Another area with potential for advances is downscaling and bias correction, which is often done in a univariate way and without consideration of spatial and temporal correlation. Converting these approaches to joint variables and retaining evolving spatial and temporal correlations is nontrivial, especially where links to underlying drivers are poorly understood or the drivers are poorly simulated (see [131] for a review of statistical techniques that can be applied to compound events). The next section describes another area seeing rapid advances: impacts of extreme heat.

\section{Impacts}

The pivot by the climate-science community from mean change to extreme heat projections has mirrored a similar shift in climate impact research: there is a growing understanding that many systems experience nonlinear increases in impacts and vulnerability during extreme heat events. A brief review is provided below for three sectors - agriculture, ecosystems, and human health - but impacts extend to other sectors (e.g., infrastructure), and sectors are not independent. For example, heat events raise demand for electricity while straining generating stations and transmission equipment, thereby increasing the risk of power failures at precisely the times when the loss of air conditioning could have the biggest impact on human mortality. The large economic and societal impacts of extreme heat across sectors is another common theme; for example, extreme heat can increase the price of electricity [132], decrease labor productivity [120], and affect social stability and violent crime rates [133]. In the small city of Zaragoza, Spain, the cost of heat events in terms of health-related impacts alone was estimated at approximately USD $\$ 100,000$ per year [134].

\section{Agriculture}

Extreme heat events pose a major risk to global crop production systems, with implications for food security and prices $[135,136]$. The effect of extreme heat on major global staple crops has been an increasingly active area of research. Past work has tended to focus on identifying threshold temperatures for severe crop yield damage between 29 and $34{ }^{\circ} \mathrm{C}$
[137-140]. More recent studies have emphasized (1) the potentiation of extreme heat stress by water stress, pointing to the importance of irrigation [141-145], and (2) the particular vulnerability of crops at the reproductive stage of growth [146-149].

Crops in developing countries of the tropics and in major breadbaskets in the USA and Russia are projected to be at particular risk to heat stress in the coming century [146, 147, 150]. Major sources of uncertainty in projected impacts of extreme heat on crops include the parameterization of $\mathrm{CO}_{2}$ fertilization, measurement and representation of extreme temperatures in field conditions, and assumptions about present and future crop management [146, 151, 152]. Relatively less attention has been afforded to nonstaple crops such as legumes, fruits, and vegetables. Assessments of extreme heat effects on livestock have focused on historical reductions in dairy and meat production $[153,154]$ and increased livestock mortality [155-158] during heat events.

\section{Ecosystems}

Extreme heat events can affect terrestrial ecosystems directly by damaging or killing organisms and indirectly by raising their vulnerability to subsequent disturbances such as disease, pests, fire, and drought [159-162]. While rising incidence of direct forest damage and die-back has been strongly connected to parallel trends in extreme heat incidence [163-166], grassland ecosystems are less clearly affected by extreme heat, especially in the absence of drought [167-170]. Vegetation disturbance from extreme heat generally reduces net ecosystem productivity and may amplify positive climate-carbon cycle feedbacks $[159,163,170-174]$, especially in coincidence with drought [173]. Central uncertainties sorrounding future extreme heat impacts on ecosystems persist concerning physiological responses and tolerance to heat, genetic and ecological capacity for adaptation, and future plantphysiology benefits of $\mathrm{CO}_{2}$ fertilization $[160,162,163,175]$.

\section{Human Health}

Extreme heat can cause mortality and hospitalizations both directly, due to hyperthermia and related acute illness, and indirectly, for example by exacerbating preexisting conditions such as cardiovascular and pulmonary illnesses. Around the world, all-cause, all-age mortality rises $1-3 \%$ per $1{ }^{\circ} \mathrm{C}$ above the local "unusually hot" threshold (which is lower in colder climates and areas with less capacity to adapt) $[176,177]$. This mortality risk varies significantly within individual cities, for instance along socioeconomic gradients-including income and access to air conditioning - as well as based on physical neighborhood features such as impervious land cover, which can further boost local surface air temperatures [178]. It should be noted that moderate summer warmth, separate from 
extreme heat events per se, accounts for a significant percentage of total heat-related mortality, especially when it persists for unusually long periods [176, 177]. While virtually all studies project increasing heat-related deaths due to climate change, a limited few project that regions with cold winters could see a decrease in net annual temperature-related deaths with climate change [179, 180]. Key research topics include (1) the extent to which adaptation has reduced or will reduce vulnerability in the future, (2) interaction of extreme heat health impacts with confounding (and often positively correlated) factors including poor air quality and compromised infrastructure performance, (3) differences in vulnerability across subpopulations, and (4) whether the traditional empirical regressions between temperature and human health outcomes are able to capture impacts at the far tail of the temperature distribution.

Given the plethora of negative impacts described above, one might fairly ask whether extreme heat events may produce any positive impacts. In contrast to mean warming, for which some potentially important positive impacts have been proposed (such as boosts to agricultural yields in areas with cool summers [181]), no proposed heat event benefits have merited a mention in major assessments such as SREX Chapter 4 [78]. However, small-scale and short-term benefits can certainly be imagined - such as increased revenue in beach communities and other cool locations like water parks, or, somewhat ironically, revenue associated with air conditioning sales.

\section{Conclusions and Future Work}

Recent studies have illuminated how the relatively small amount of anthropogenic climate change to date has already led to large increases in the frequency of heat events. This combination of high sensitivity to mean warming, and large impacts, makes heat a prime if underappreciated example of the danger associated with greenhouse gas emissions in excess of the $1.5{ }^{\circ} \mathrm{C}$ warming goal outlined at the twenty-first Conference of the Parties in Paris. The tropics and subtropics especially are areas of high concern even under modest warming: the combination of high baseline temperature and low variability is projected to yield large changes in recurrence frequencies of heat extremes. As the techniques of event attribution advance, quantifications of the losses and damages associated with extreme heat may in due course receive more attention. The tropics and subtropics are likely to be a continued focus, given large vulnerabilities and-with notable exceptions - relatively low culpability in terms of cumulative greenhouse gas emissions.

This review points to large but difficult-to-quantify tail risks of heat extremes, tail risks that would be reduced through mitigation. Two potential high consequence outcomes that, while still characterized by significant "two-tailed" uncertainty, show signs of right tail risk are (1) more rapid changes in heat event-supporting mechanisms (such as soil moisture anomalies or planetary wave configurations described in the section "Mechanisms Underpinning Heat Events") than are projected by current models, and (2) strong positive correlations between compound extremes, such as (a) heat events concurrent and collocated with either high humidity or drought, or (b) temporally and spatially correlated heat events (or heat events and other types of extremes), which could pose systemic risks to global food security, and the reinsurance industry, for example. With respect to (1), evidence for dynamical changes in summer may exceed the more publicized winter case, since natural variability is so much lower in summer. In terms of soil moisture/land surface feedbacks, it is important to note that some studies have found GCM overestimation of historical trends in extreme heat [82, 182-184]. Overestimation of land-atmosphere feedbacks associated with dry and or hot extremes has been found in global [185] and regional models [186] as well, leading to excessive warm biases during heat events that may be amplified in future projections of extreme heat. Along the same lines, with respect to (2), it is far from certain that the frequency of future compound extremes will exceed the increase expected due to mean temperature shifts alone. Much of the argument for further research on (1) and (2) is based precisely on the large uncertainties, and consequences should "high-tail" outcomes occur.

The following topics appear ripe for future research:

Data collection and research on heat events in the tropics and southern hemisphere: While there is substantial and growing literature about northern hemisphere midlatitude heat events, more research is needed on the mechanisms behind tropical, subtropical, and southern hemisphere midlatitude heat extremes in current and future climates. Heat wave mechanisms: The complex nature of the dynamics behind heat extremes indicates a need for standardized methods of analysis and definitions. The combination of large natural variability, short duration of records, small sample sizes of extreme states, and system complexity all point to the need for more studies using models of varying complexity. Yet, the above characteristics also make it difficult to ascertain whether models are missing key processes that support heat extremes. Model improvements in the simulation of climatological features (e.g., tropical convection patterns, midlatitude storm tracks, subtropical jet streams, and jet exit regions [76]) are a likely prerequisite to improved simulation of midlatitude blocking and heat events in current and ultimately future climates [40]. To the extent that coupled models (inevitably) continue to fail to capture the full range of possible outcomes for important forcings such as tropical SST gradients and Arctic sea ice loss, tailored 
experiments with atmospheric models and specified lower boundary conditions may offer some insights into heat events (albeit in the absence of potentially important coupling). Similar arguments can be applied to the importance of realistic simulation of soil moisture extremes, as land-surface models parameterize important soilcolumn and vegetative physics. Still, it is worth noting that relative to some other types of extremes that tend to be more local in nature than heat events (e.g., severe convective systems), the potential for model insights into future heat event behavior may be relatively high [187]. Compound extremes: No framework currently exists to help identify a priori which heat-related compounds are most likely to fatten the tail of heat-related risks. Future research could also help unpack the extent to which observed or projected changes in compound extremes might be due to (a) statistical artifacts of mean shifts alone or (b) changes in processes that physically link extreme heat events in space and time, or physically link heat extremes to other types of extremes. There is also a need for downscaling techniques that do not by default treat these same variables and spatiotemporal relationships as independent.

Spatial scale: More research is needed on how urban landscapes, future vegetation changes, and intensive crop production may interact with extreme heat. This topic has major environmental justice implications, given large populations exposed to elevated heat in many urban communities. There is also a need for high-resolution modeling and observational studies of the extent to which exceptionally high wet-bulb temperatures associated with anomalously high near-coastal SSTs may be able to penetrate inland in different areas, potentially interacting with hot but dry air masses. This question is of particular timeliness given reports that the highest wet-bulb temperatures of $34.6{ }^{\circ} \mathrm{C}$ during the extreme Middle Eastern heatwave of July 2015 were $30 \mathrm{~km}$ inland rather than immediately at the coast [188]. At the other end of the spatial spectrum, there has been very little research into just how much the areal extent of heat waves might grow, which is perhaps surprising given the large attention paid to other heat event characteristics (such as magnitude, frequency, and duration). Any increases in areal extent could for example have major implications for electric sector reliability, health care/emergency management, and regional agriculture and food security.

Predictability: Because human interventions are known to reduce heat event impacts, research is needed on whether the recent suggestions of some heat wave predictability 2-7 weeks in advance can be extended to other regions $[20,74]$. More research is also needed on whether climate change may modify heat event predictability at both weather and seasonal timescales.
Adaptation to heat events: As heat event and heat eventimpact research advances, it is critical that the emerging science of adaptation to heat extremes be documented and evaluated rigorously as well. This after all is the mechanism by which the scientific understanding of heat events will ultimately be brought to bear on ameliorating their deleterious effects on the people, infrastructure, and biosphere of the twenty-first-century world.

\section{Compliance with Ethical Standards}

Conflict of Interest On behalf of all authors, the corresponding author states that there is no conflict of interest.

Open Access This article is distributed under the terms of the Creative Commons Attribution 4.0 International License (http:// creativecommons.org/licenses/by/4.0/), which permits unrestricted use, distribution, and reproduction in any medium, provided you give appropriate credit to the original author(s) and the source, provide a link to the Creative Commons license, and indicate if changes were made.

\section{References}

1. García-Herrera R, Díaz J, Trigo RM, Luterbacher J, Fischer EM. A review of the European summer heat wave of 2003. Crit Rev Environ Sci Technol. 2010;40:267-306. doi:10.1080/10643380802238137.

2. Shaposhnikov D, Revich B, Bellander T, Bedada GB, Bottai M, Kharkova T, et al. Mortality related to air pollution with the Moscow heat wave and wildfire of 2010. Epidemiology. 2014;25:359-64. doi:10.1097/EDE.0000000000000090.

3. Robine J, Lan S, Cheung K, Le S, Van Oyen H, Griffiths C, et al. Death toll exceeded 70,000 in Europe during the summer of 2003. C R Biol. 2008;331:171-8. doi:10.1016/j.crvi.2007.12.001.

4. Wegren SK. Food security and Russia's 2010 drought. Eurasian Geogr Econ. 2013;52(1):140-56.

5. Perkins SE. A review on the scientific understanding of heatwaves - their measurement, driving mechanisms, and changes at the global scale. Atmos Res. 2015;164-165:242-67. doi:10.1016/j.atmosres.2015.05.014.

6. Davis RE, McGregor GR, Enfield KB. Humidity: a review and primer on atmospheric moisture and human health. Environ Res. 2016;144:106-16. doi:10.1016/j.envres.2015.10.014.

7. Gao Y, Fu JS, Drake JB, Liu Y, Lamarque J. Projected changes of extreme weather events in the eastern United States based on a high resolution climate modeling system. Environ Res Lett. 2012;7:1-12. doi:10.1088/1748-9326/7/4/044025.

8. Katz RW, Grotjahn R. Statistical methods for relating temperature extremes to large-scale meteorological patterns. US Clivar Var. 2014;12:4-7.

9. Hass AL, Ellis KN, Mason LR, Hathaway JM, Howe DA. Heat and humidity in the city: neighborhood heat index variability in a mid-sized city in the southeastern United States. Int J Environ Res Public Health. 2016;13:1-19. doi:10.3390/ijerph13010117.

10. Stott PA, Stone DA, Allen MR. Human contribution to the European heatwave of 2003. Nature. 2004;432:610-4. doi:10.1038/nature03089.

11. Anderson BG, Bell ML. Weather-related mortality: how heat, cold, and heat waves affect mortality in the United States Brooke. Epidemiology. 2009;20:205-13. doi:10.1016/j.surg.2006.10.010. 
12. Kunreuther H, Heal G, Allen MR, Edenhofer O, Field CB, Yohe G. Risk management and climate change. Nat Clim Chang. 2013;3:447-50. doi:10.1038/nclimate1740.

13. Russo S, Dosio A, Graversen RG, Sillmann J, Carrao H, Dunbar $\mathrm{MB}$, et al. Magnitude of extreme heat waves in present climate and their projection in a warming world. J Geophys Res Atmos. 2014;119:500-12. doi:10.1002/2014JD022098.

14. Russo S, Dosio A, Sillmann J. Top ten European heatwaves since 1950 and their occurrence in the future. Environ Res Lett. 2010;10:124003. doi:10.1088/1748-9326/10/12/124003.

15. Coumou D, Robinson A. Historic and future increase in the global land area affected by monthly heat extremes. Environ Res Lett. 2013;8:34018. doi:10.1088/1748-9326/8/3/034018.

16. Coumou D, Robinson A, Rahmstorf S. Global increase in recordbreaking monthly-mean temperatures. Clim Chang. 2013;118: 771-82. doi:10.1007/s10584-012-0668-1.

17. Petoukhov V, Rahmstorf S, Petri S, Schellnhuber HJ. Quasiresonant amplification of planetary waves and recent Northern Hemisphere weather extremes. Proc Natl Acad Sci U S A. 2013;110:5336-41. doi:10.1073/pnas.1222000110.

18. Screen JA, Simmonds I. Amplified mid-latitude planetary waves favour particular regional weather extremes. Nat Clim Chang. 2014;4:704-9. doi:10.1038/NCLIMATE2271.

19. Barnes EA, Dunn-Sigouin E, Masato G, Woollings T. Exploring recent trends in Northern Hemisphere blocking. Geophys Res Lett. 2014;41:638-44. doi:10.1002/2013GL058745.

20. Teng H, Branstator G, Wang H, Meehl GA, Washington WM. Probability of US heat waves affected by a subseasonal planetary wave pattern. Nat Geosci. 2013;6:1-6. doi:10.1038/ngeo1988.

21. Coumou D, Petoukhov V, Rahmstorf S, Petri S, Schellnhuber HJ. Quasi-resonant circulation regimes and hemispheric synchronization of extreme weather in boreal summer. Proc Natl Acad Sci. 2014;111:12331-6. doi:10.1073/pnas.1412797111.

22. Cohen J, Screen JA, Furtado JC, Barlow M, Whittleston D, Coumou $\mathrm{D}$, et al. Recent Arctic amplification and extreme mid-latitude weather. Nat Geosci. 2014;7:627-37. doi:10.1038/ngeo2234.

23. Coumou D, Lehmann J, Beckmann J. The weakening summer circulation in the Northern Hemisphere mid-latitudes. Science. 2015;348(80):324-7. doi:10.1126/science.1261768.

24. Lehmann J, Coumou D. The influence of mid-latitude storm tracks on hot, cold, dry, and wet extremes. Nat Sci Rep. 2015;5. doi:10.1038/srep17491.

25. Lehmann J, Coumou D, Frieler K, Eliseev AV, Levermann A. Future changes in extratropical storm tracks and baroclinicity under climate change. Environ Res Lett. 2014;9:084002. doi:10.1088/1748-9326/9/8/084002.

26. Lau NC, Nath MJ. A model study of heat waves over North America: meteorological aspects and projections for the twenty-first century. $\mathrm{J}$ Climate. 2012;25:4761-4. doi:10.1175/JCLI-D-11-00575.1.

27. Lee Y-Y, Grotjahn R. California central valley summer heat waves form two ways. J Climate. 2016;29:1201-17. doi:10.1175/JCLI-D-15-0270.1.

28. Grotjahn R, Black R, Leung R, Wehner MF, Barlow M, Bosilovich $\mathrm{M}$, et al. North American extreme temperature events and related large scale meteorological patterns: a review of statistical methods, dynamics, modeling, and trends. Clim Dyn. 2015;46:1151-84. doi:10.1007/s00382-015-2638-6.

29. Zampieri M, D'Andrea F, Vautard R, Ciais P, De NobletDucoudré N, Yiou P. Hot European summers and the role of soil moisture in the propagation of Mediterranean drought. J Climate. 2009;22:4747-58. doi:10.1175/2009JCLI2568.1.

30. Fischer EM, Seneviratne SI, Vidale PL, Lüthi D, Schär C. Soil moisture-atmosphere interactions during the European summer heat wave. J Climate. 2003;20(2007):5081-99. doi:10.1175/JCLI4288.1.

31. Stéfanon M, Drobinski P, D'Andrea F, De Noblet-Ducoudré N. Effects of interactive vegetation phenology on the 2003 summer heat waves. J Geophys Res Atmos. 2012;117:1-15. doi:10.1029/2012JD018187.
32. Miralles DG, Teuling AJ, Van Heerwaarden CC. Mega-heatwave temperatures due to combined soil desiccation and atmospheric heat accumulation. Nat Geosci. 2014;7:345-9. doi:10.1038/ngeo2141.

33. Mueller ND, Butler EE, McKinnon KA, Rhines A, Tingley M, Holbrook NM, et al. Cooling of US Midwest summer temperature extremes from cropland intensification. Nat Clim Chang. 2015. doi: $10.1038 /$ nclimate 2825 .

34. Barnes EA, Slingo J, Woollings T. A methodology for the comparison of blocking climatologies across indices, models and climate scenarios. Clim Dyn. 2012;38:2467-81. doi:10.1007 /s00382-011-1243-6.

35. Pfahl S, Schwierz C, Croci-Maspoli M, Grams CM, Wernli H. Importance of latent heat release in ascending air streams for atmospheric blocking. Nat Geosci. 2015;8:610-4. doi:10.1038 /ngeo2487.

36. Photiadou C, Jones MR, Keellings D, Dewes CF. Modeling European hot spells using extreme value analysis. Clim Res. 2014;58:193-207. doi:10.3354/cr01191.

37. Schubert S, Wang H, Suarez M. Warm season subseasonal variability and climate extremes in the northern hemisphere: the role of stationary Rossby waves. J Climate. 2011;24:4773-92. doi:10.1175/JCLI-D-10-05035.1.

38. Horton DE, Johnson NC, Singh D, Swain DL, Rajaratnam B, Diffenbaugh NS. Contribution of changes in atmospheric circulation patterns to extreme temperature trends. Nature. 2015;522: 465-9. doi:10.1038/nature14550.

39. Fischer EM, Knutti R. Anthropogenic contribution to global occurrence of heavy-precipitation and high-temperature extremes. Nat Clim Chang. 2015;5:1-6. doi:10.1038/nclimate2617.

40. Hoskins BJ, Woollings T. Persistent extratropical regimes and climate extremes. Curr Clim Chang Rep. 2015;1:115-24. doi:10.1007/s40641-015-0020-8.

41. Hoskins BJ. Dynamical processes in the atmosphere and the use of models. Q J Roy Meteorol Soc. 1983;109:1-21.

42. Hassanzadeh P, Kuang Z. Blocking variability: Arctic amplification versus arctic oscillation. Geophys Res Lett. 2015;42:858695. doi:10.1002/2015GL065923.Abstract.

43. Barnes EA, Screen JA. The impact of Arctic warming on the midlatitude jet-stream: can it? Has it? Will it? Wiley Interdiscip Rev Clim Chang. 2015;6:277-86. doi:10.1002/wcc.337.

44. Petoukhov V, Rahmstorf S, Petri S, Schellnhuber HJ. Reply to Screen and Simmonds: From means to mechanisms. Proc Natl Acad Sci. 2013;1073. doi:10.1073/pnas.1305595110.

45. Branstator G. Circumglobal teleconnections, the jet stream waveguide, and the North Atlantic oscillation. J Climate. 2002;15: 1893-910.

46. Screen JA, Simmonds I. Caution needed when linking weather extremes to amplified planetary waves. Proc Natl Acad Sci U S A. 2013;110:E2327. doi:10.1073/pnas.1304867110.

47. Liu J, Song M, Horton RM, Hu Y. Reducing spread in climate model projections of a September ice-free Arctic. Proc Natl Acad Sci U S A. 2013;110:12571-6. doi:10.1073/pnas.1219716110.

48. Liu J, Curry JA, Wang H, Song M, Horton RM. Impact of declining Arctic sea ice on winter snowfall. Proc Natl Acad Sci. 2012;109:4074-9.

49. Francis JA, Vavrus SJ. Evidence linking Arctic amplification to extreme weather in mid-latitudes. Geophys Res Lett. 2012;39. doi:10.1029/2012GL051000.

50. Barnes EA. Revisiting the evidence linking Arctic amplification to extreme weather in midlatitudes. Geophys Res Lett. 2013. doi:10.1002/grl.50880.

51. Barnes EA, Polvani L. Response of the midlatitude jets, and of their variability, to increased greenhouse gases in the CMIP5 models. J Climate. 2013;26:7117-35. doi:10.1175/JCLI-D-1200536.1. 
52. Wallace JM, Held IM, Thompson DWJ, Trenberth KE, Walsh J. Global warming and winter weather. Science. 2014;343(80):72930 .

53. Tang Q, Zhang X, Francis JA. Extreme summer weather in northern mid-latitudes linked to a vanishing cryosphere. Nat Clim Chang. 2013;4:45-50. doi:10.1038/nclimate2065.

54. Teng H, Branstator G, Meehl GA, Washington WM. Projected intensification of subseasonal temperature variability and heat waves in the Great Plains. Geophys Res Lett. 2016. doi:10.1002 /2015GL067574.

55. Ding Q, Wallace JM, Battisti DS, Steig EJ, Gallant AJE, Kim H-J, et al. Tropical forcing of the recent rapid Arctic warming in northeastern Canada and Greenland. Nature. 2014;509:209-12. doi:10.1038/nature13260.

56. Dawson A, Palmer TN. Simulating weather regimes: impact of model resolution and stochastic parameterization. Clim Dyn. 2015;44:2177-93. doi:10.1007/s00382-014-2238-x.

57. Dunn-Sigouin E, Son SW. Northern hemisphere blocking frequency and duration in the CMIP5 models. J Geophys Res Atmos. 2013;118:1179-88. doi:10.1002/jgrd.50143.

58. Masato G, Hoskins BJ, Woollings T. Winter and summer northern hemisphere blocking in CMIP5 models. J Climate. 2013;26: 7044-59. doi:10.1175/JCLI-D-12-00466.1.

59. Cook BI, Ault TR, Smerdon JE. Unprecedented 21st century drought risk in the American Southwest and Central Plains. Sci Adv. 2015;1, e1400082.

60. Seneviratne SI, Lüthi D, Litschi M, Schär C. Land-atmosphere coupling and climate change in Europe. Nature. 2006;443:2059. doi:10.1038/nature05095.

61. Seneviratne SI, Corti T, Davin EL, Hirschi M, Jaeger EB, Lehner $\mathrm{I}$, et al. Investigating soil moisture-climate interactions in a changing climate: a review. Earth Sci Rev. 2010;99:125-61. doi:10.1016/j.earscirev.2010.02.004.

62. Dirmeyer PA, Cash BA, Kinter JL, Stan C, Jung T, Marx L, et al. Evidence for enhanced land-atmosphere feedback in a warming climate. J Hydrometeorol. 2012;13:981-95. doi:10.1175/JHM-D11-0104.1.

63. Kala J, De Kauwe MG, Pitman AJ, Medlyn BE, Wang Y, Lorenz $\mathrm{R}$, et al. Impact of the representation of stomatal conductance on model projections of heatwave intensity. Sci Rep. 2016;6:1-7. doi:10.1038/srep23418.

64. Seager R, Naik N, Vecchi GA. Thermodynamic and dynamic mechanisms for large-scale changes in the hydrological cycle in response to global warming. J Climate. 2010;23:4651-68. doi:10.1175/2010JCLI3655.1.

65. Dai AG. Increasing drought under global warming in observations and models. Nat Clim Chang. 2013;3:52-8. doi:10.1038 /nclimate1633.

66. Singh D, Tsiang M, Rajaratnam B, Diffenbaugh NS. Precipitation extremes over the continental United States in a transient, highresolution, ensemble climate model experiment. J Geophys Res Atmos. 2013;118:7063-86. doi:10.1002/jgrd.50543.

67. Vautard R, Yiou P, Andrea FD, De Noblet N, Viovy N, Cassou C, et al. Summertime European heat and drought waves induced by wintertime Mediterranean rainfall deficit. Geophys Res Lett. 2007;34:1-5. doi:10.1029/2006GL028001.

68. Xu Y, Lamarque J, Sanderson BM. The importance of aerosol scenarios in projections of future heat extremes. Clim Change. 2015. doi:10.1007/s10584-015-1565-1.

69. Lenderink G, van Ulden A, van Meijgaard E, van den Hurk B. Summertime inter-annual temperature variability in an ensemble of regional model simulations: analysis of the surface energy budget. Clim Change. 2007;81:233-47. doi:10.1007/s10584-0069229-9.

70. Holmes CR, Woollings T, Hawkins E, de Vries H. Robust future changes in temperature variability under greenhouse gas forcing and the relationship with thermal advection. J Climate. 2015;29: 2221-36. doi:10.1175/JCLI-D-14-00735.1.

71. Watterson IG, Mcgregor JL, Nguyen KC. Changes in extreme temperatures of Australasian summer simulated by CCAM under global warming, and the roles of winds and land-sea contrasts. Aust Meteorol Mag. 2008;57:195-212.

72. Shaw TA, Voigt A. Tug of war on summertime circulation between radiative forcing and sea surface warming. Nat Geosci. 2015;8:560-6. doi:10.1038/ngeo2449.

73. IPCC: Working Group I Contribution to the IPCC Fifth Assessment Report- summary for policymakers. Clim Chang Phys Sci Basis. 2013;1-36. doi:10.1017/CBO9781107415324.004.

74. Mckinnon KA, Rhines A, Tingley MP, Huybers P. Long-lead predictions of eastern United States hot days from Pacific sea surface temperatures. Nat Geosci. 2016;9:389-96. doi:10.1038 /NGEO2687.

75. Trenberth KE, Fasullo JT, Shepherd TG. Attribution of climate extreme events. Nat Clim Chang. 2015;5:725-30. doi:10.1038 /nclimate2657.

76. Grotjahn R, Black R, Leung R, Wehner MF, Barlow M, Bosilovich M, et al. North American extreme temperature events and related large scale meteorological patterns: a review of statistical methods, dynamics, modeling, and trends. Berlin: Springer; 2015. doi:10.1007/s00382-015-2638-6.

77. Donat MG, Peterson TC, Brunet M, King AD, Almazroui M, Kolli $\mathrm{RK}$, et al. Changes in extreme temperature and precipitation in the Arab region: long-term trends and variability related to ENSO and NAO. Int J Climatol. 2014;34:581-92. doi:10.1002/joc.3707.

78. Field CB, Intergovernmental Panel on Climate Change. Managing the risks of extreme events and disasters to advance climate change adaptation: special report of the Intergovernmental Panel on Climate Change. 2012. doi:10.1017/CBO9781139177245.

79. Coumou D, Rahmstorf S. A decade of weather extremes. Nat Clim Chang. 2012. doi:10.1038/nclimate1452.

80. Rahmstorf S, Coumou D. Increase of extreme events in a warming world. Proc Natl Acad Sci U S A. 2011;108:17905-9. doi:10.1073 /pnas.1101766108.

81. Mishra V, Ganguly AR, Nijssen B, Lettenmaier DP. Changes in observed climate extremes in global urban areas. Environ Res Lett. 2015;10. doi:10.1088/1748-9326/10/2/024005.

82. Fischer EM, Knutti R. Detection of spatially aggregated changes in temperature and precipitation extremes. Geophys Res Lett. 2014;41:547-54. doi:10.1002/2013GL058499.

83. Lewis SC, Karoly DJ. Anthropogenic contributions to Australia's record summer temperatures of 2013. Geophys Res Lett. 2013;40: 3708-9. doi:10.1002/grl.50673.

84. Lewis SC, King AD. Dramatically increased rate of observed hot record breaking in recent Australian temperatures. Geophys Res Lett. 2015;42:7776-84. doi:10.1002/2015GL065793.Received.

85. Seneviratne SI, Donat MG, Mueller B, Alexander LV. No pause in the increase of hot temperature extremes. Nat Clim Chang. 2014;4:161-3. doi:10.1038/nclimate2145.

86. Gallant AJE, Karoly DJ, Gleason KL. Consistent trends in a modified climate extremes index in the United States, Europe, and Australia. J Climate. 2014;27:1379-94. doi:10.1175/JCLI-D-1200783.1.

87. IPCC. Managing the risks of extreme events and disasters to advance climate change adaptation. Cambridge: Cambridge University Press; 2012. doi:10.1017/CBO9781139177245.

88. Hansen G, Auffhammer M, Solow AR. On the attribution of a single event to climate change. J Climate. 2014;27:8297-302. doi:10.1175/JCLI-D-14-00399.1.

89. Solow BAR. Extreme weather, made by us? Science. 2015;349(80):1444-5. 
90. Shepherd TG. A common framework for approaches to extreme event attribution. Curr Clim Chang Rep. 2016;2:28-38. doi:10.1007/s40641-016-0033-y.

91. Herring SC, Hoerling MP, Peterson TC, Stott PA. Explaining extreme events of 2013 from a climate perspective. Bull Am Meteorol Soc. 2014;95:S1-S96.

92. Herring SC, Hoerling MP, Kossin JP, Peterson TC, Stott PA. Explaining extreme events of 2014 from a climate perspective. Bull Am Meteorol Soc. 2015;96:S1-S172.

93. Stocker T, Field C, Dahe Q, Barros V, Plattner G-K, Tignor M, et al. IPCC expert meeting on detection and attribution related to anthropogenic climate change. 2009;65. http://nova.wh.whoi. edu/palit/Stockeretal._2009_Report_IPCC Expert Meeting on Detection and Attribution Related to Anthropogenic Climate Change.

94. Knutson TR, Ploshay JJ. Detection of anthropogenic influence on a summertime heat stress index. Clim Change. 2016. doi:10.1007 /s10584-016-1708-z.

95. Herring SC, Hoerling MP, Peterson TC, Stott PA. Explaining extreme events of 2013 from a climate perspective. Bull Am Meteorol Soc. 2014;95.

96. Diffenbaugh NS, Swain DL, Touma D. Anthropogenic warming has increased drought risk in California. Proc Natl Acad Sci. 2015;201422385. doi:10.1073/pnas.1422385112.

97. Hansen G, Auffhammer M, Solow AR. On the attribution of a single event to climate change. J Clim 2014;141006071055006. doi:10.1175/JCLI-D-14-00399.1.

98. Stott P. Weather risks in a warming world. Nat Clim Chang. 2015;5:516-7. doi:10.1038/nclimate2640.

99. Loikith PC, Waliser DE, Lee H, Neelin JD, Lintner BR, McGinnis $\mathrm{S}$, et al. Evaluation of large-scale meteorological patterns associated with temperature extremes in the NARCCAP regional climate model simulations. Clim Dyn. 2015;45:3257-74. doi:10.1007/s00382-015-2537-x.

100. Alexander L, Perkins S. Debate heating up over changes in climate variability. Environ Res Lett. 2013;8:41001. doi:10.1088/17489326/8/4/041001.

101. Perkins SE, Alexander LV. On the measurement of heat waves. J Climate. 2013;26:4500-17. doi:10.1175/JCLI-D-12-00383.1.

102. Otto FEL, Massey N, Van Oldenborgh GJ, Jones RG, Allen MR. Reconciling two approaches to attribution of the 2010 Russian heat wave. Geophys Res Lett. 2012;39:1-5. doi:10.1029/2011 GL050422.

103. Dole R, Hoerling MP, Perlwitz J, Eischeid J, Pegion P, Zhang T, et al. Was there a basis for anticipating the 2010 Russian heat wave? Geophys Res Lett. 2011;38. n/a-n/a. doi:10.1029/2010 GL046582.

104. Kim Y-H, Min S-K, Zhang X, Zwiers F, Alexander LV, Donat MG, et al. Attribution of extreme temperature changes during 1951-2010. Clim Dyn. 2015;1-14. doi:10.1007/s00382-0152674-2.

105. Christidis N, Stott PA, Hegerl GC, Betts RA, Brown SJ. The role of land use change in the recent warming of daily extreme temperatures. Geophys Res Lett. 2013;40. n/a-n/a. doi:10.1002 /grl.50159.

106. Coumou D, Robinson A. Historic and future increase in the global land area affected by monthly heat extremes. Environ Res Lett. 2013;8:034018. doi:10.1088/1748-9326/8/3/034018.

107. Kunkel KE, Vose RS, Stevens LE, Knight RW. Is the monthly temperature climate of the United States becoming more extreme? Geophys Res Lett. 2015;42:629-36. doi:10.1002/2014 GL062035.

108. Rhines A, Huybers P. Frequent summer temperature extremes reflect changes in the mean, not the variance. Proc Natl Acad Sci. 2013;110:E546-6. doi:10.1073/pnas.1218748110.
109. Huntingford C, Jones PD, Livina VN, Lenton TM, Cox PM. No increase in global temperature variability despite changing regional patterns. Nature. 2013;500:327-30. doi:10.1038/nature12310.

110. Kodra E, Ganguly AR. Asymmetry of projected increases in extreme temperature distributions. Sci Rep. 2014;4:5884. doi:10.1038/srep05884.

111. Horton RM, Coffel ED, Winter JM, Bader DA, Al HET. Projected changes in extreme temperature events based on the NARCCAP model suite. Geophys Res Lett. 2015;42:7722-31. doi:10.1002 /2015GL064914.Once-per-year.

112. Sillmann J, Kharin VV, Zwiers FW, Zhang X, Bronaugh D. Climate extremes indices in the CMIP5 multimodel ensemble: part 2. Future climate projections. J Geophys Res Atmos. 2013;118:2473-93. doi:10.1002/jgrd.50188.

113. Hawkins E, Sutton R. Time of emergence of climate signals Geophys Res Lett. 2012;39:1-6. doi:10.1029/2011GL050087.

114. Russo S, Marchese AF, Giuseppina JS. When will unusual heat waves become normal in a warming Africa? Environ Res Lett. 2015;11:1-22. doi:10.1088/1748-9326/11/5/054016.

115. Cowan T, Purich A, Perkins S, Pezza A, Boschat G, Sadler K. More frequent, longer, and hotter heat waves for Australia in the twenty-first century. J Climate. 2014;27:5851-71. doi:10.1175 /JCLI-D-14-00092.1.

116. Bador M, Terray L, Boé J. Emergence of human influence on summer record-breaking temperatures over Europe. Geophys Res Lett. 2015. doi:10.1002/2015GL066560.

117. King AD, Donat MG, Fischer EM, Hawkins E, Alexander LV, Karoly DJ. The timing of anthropogenic emergence in simulated climate extremes. Environ Res Lett. 2015;10:94015. doi:10.1088 /1748-9326/10/9/094015.

118. Little CM, Horton RM, Kopp RE, Oppenheimer M, Vecchi GA, Villarini G. Joint projections of US East Coast sea level and storm surge. Nat Clim Chang. 2015;5:1-8. doi:10.1038 /NCLIMATE2801.

119. Sherwood SC, Huber M. An adaptability limit to climate change due to heat stress. Proc Natl. 2010;107:9552-5. doi:10.1073 /pnas.0913352107/-/DCSupplemental.www.pnas. org/cgi/doi/10.1073/pnas.0913352107.

120. Dunne JP, Stouffer RJ, John JG. Reductions in labour capacity from heat stress under climate warming. Nat Clim Chang. 2013;3:563-6. doi:10.1038/nclimate1827.

121. Pal JS, Eltahir EAB. Future temperature in southwest Asia projected to exceed a threshold for human adaptability. Nat Clim Chang. 2015. doi:10.1038/nclimate2833.

122. Alroy J. Cope's rule and the dynamics of body mass evolution in North American fossil mammals. Science. 1998;280(80):731-4.

123. Caulfield MP, Cambridge H, Foster SF, McGreevy PD. Heat stress: a major contributor to poor animal welfare associated with long-haul live export voyages. Vet J. 2014;199:223-8. doi:10.1016/j.tvj1.2013.09.018.

124. Fischer EM, Knutti R. Robust projections of combined humidity and temperature extremes. Nat Clim Chang. 2012;3:1-5. doi:10.1038/nclimate1682.

125. AghaKouchak A, Cheng L, Mazdiyasni O, Farahmand A. Global warming and changes in risk of concurrent climate extremes: insights from the 2014 California drought. Geophys Res Lett. 2014;41:2014GL062308. doi:10.1002/2014GL062308.

126. Trenberth KE, Shea DJ. Relationships between precipitation and surface temperature. Geophys Res Lett. 2005;32:1-4. doi:10.1029 /2005GL022760.

127. Mazdiyasni O, AghaKouchak A. Substantial increase in concurrent droughts and heatwaves in the United States. Proc Natl Acad Sci. 2015;112:11484-9. doi:10.1073/pnas.1422945112.

128. Kossin JP. Is the North Atlantic hurricane season getting longer? Geophys Res Lett. 2008;35:3-5. doi:10.1029/2008GL036012. 
129. Horton RM, Liu J. Beyond hurricane sandy: what might the future hold for tropical cyclones in the North Atlantic? J Extremes Events. 2014. doi:10.1142/S2345737614500079.

130. Trenberth KE, Fasullo JT. Climate extremes and climate change: the Russian heat wave and other climate extremes of 2010. J Geophys Res Atmos. 2012;117:1-12. doi:10.1029/2012 JD018020.

131. Leonard M, Westra S, Phatak A, Lambert M, van den Hurk B, Mcinnes K, et al. A compound event framework for understanding extreme impacts. Wiley Interdiscip Rev Clim Chang. 2014;5:11328. doi:10.1002/wcc.252.

132. Pechan A, Eisenack K. The impact of heat waves on electricity spot markets. Energy Econ. 2014;43:63-71. doi:10.1016/j. eneco.2014.02.006.

133. Ranson M. Crime, weather, and climate change. J Environ Econ Manag. 2014;67:274-302. doi:10.1016/j.jeem.2013.11.008.

134. Roldán E, Gómez M, Pino MR, Pórtoles J, Linares C, Díaz J. The effect of climate-change-related heat waves on mortality in Spain: uncertainties in health on a local scale. Stoch Env Res Risk Assess. 2015. doi:10.1007/s00477-015-1068-7.

135. Lesk C, Rowhani P, Ramankutty N. Influence of extreme weather disasters on global crop production. Nature. 2016;529:84-7. doi:10.1038/nature16467.

136. Porter JR, Xie L, Challinor AJ, Cochrane K, Howden SM, Iqbal $\mathrm{MH}$ et al. Chapter 7. Food security and food production systems. Clim Chang Impacts Adapt Vulnerability. 2014;485-533.

137. Lobell DB, Bänziger M, Magorokosho C, Vivek B. Nonlinear heat effects on African maize as evidenced by historical yield trials. Nat Clim Chang. 2011;1:42-5. doi:10.1038/nclimate1043.

138. Lobell DB, Sibley A, Ivan Ortiz-Monasterio J. Extreme heat effects on wheat senescence in India. Nat Clim Chang. 2012;2:1869. doi:10.1038/nclimate1356.

139. Luo Q. Temperature thresholds and crop production: a review. Clim Change. 2011;109:583-98. doi:10.1007/s10584-011-00286.

140. Schlenker W, Roberts MJ. Nonlinear temperature effects indicate severe damages to U.S. crop yields under climate change. Proc Natl Acad Sci U S A. 2009;106:15594-8. doi:10.1073 pnas.0906865106.

141. Chen Y, Zhang Z, Wang P, Song X, Wei X, Tao F. Identifying the impact of multi-hazards on crop yield - a case for heat stress and dry stress on winter wheat yield in northern China. Eur J Agron. 2015. doi:10.1016/j.eja.2015.10.009.

142. Lobell DB, Hammer GL, Chenu K, Zheng B, McLean G, Chapman SC. The shifting influence of drought and heat stress for crops in Northeast Australia. Glob Chang Biol. 2015;21:411527. doi: $10.1111 / \mathrm{gcb} .13022$.

143. Lobell DB, Hammer GL, McLean G, Messina C, Roberts MJ, Schlenker W. The critical role of extreme heat for maize production in the United States. Nat Clim Chang. 2013;3:497-501. doi:10.1038/nclimate1832.

144. Troy TJ, Kipgen C, Pal I. The impact of climate extremes and irrigation on US crop yields. Environ Res Lett. 2015;10. doi:10.1088/1748-9326/10/5/054013.

145. Zhang T, Lin X, Sassenrath GF. Current irrigation practices in the central United States reduce drought and extreme heat impacts for maize and soybean, but not for wheat. Sci Total Environ. 2015;508:331-42. doi:10.1016/j.scitotenv.2014.12.004.

146. Deryng D, Conway D, Ramankutty N, Price J, Warren R. Global crop yield response to extreme heat stress under multiple climate change futures. Environ Res Lett. 2014;9:34011. doi:10.1088 /1748-9326/9/3/034011.

147. Gourdji SM, Sibley AM, Lobell DB. Global crop exposure to critical high temperatures in the reproductive period: historical trends and future projections. Environ Res Lett. 2013;8:24041. doi:10.1088/1748-9326/8/2/024041.
148. Liu B, Liu L, Tian L, Cao W, Zhu Y, Asseng S. Post-heading heat stress and yield impact in winter wheat of China. Glob Chang Biol. 2014;20:372-81. doi:10.1111/gcb.12442.

149. Rezaei EE, Siebert S, Ewert F. Intensity of heat stress in winter wheat - phenology compensates for the adverse effect of global warming. Environ Res Lett. 2015;10. doi:10.1088/1748-9326/10 /2/024012.

150. Teixeira EI, Fischer G, Van Velthuizen H, Walter C, Ewert F. Global hot-spots of heat stress on agricultural crops due to climate change. Agric For Meteorol. 2013;170:206-15. doi:10.1016/j. agrformet.2011.09.002.

151. Rosenzweig C, Elliott J, Deryng D, Ruane AC, Müller C, Arneth A, et al. Assessing agricultural risks of climate change in the 21 st century in a global gridded crop model intercomparison. Proc Natl Acad Sci U S A. 2014;111:3268-73. doi:10.1073/pnas.1222463110.

152. Siebert S, Ewert F, Rezaei EE, Kage H. Impact of heat stress on crop yield - on the importance of considering canopy temperature. Environ Res Lett. 2014;9:1-8. doi:10.1088/1748-9326/9/4/044012.

153. Dunn RJH, Mead NE, Willett KM, Parker DE. Analysis of heat stress in UK dairy cattle and impact on milk yields. Environ Res Lett. 2014;9:64006. doi:10.1088/1748-9326/9/6/064006.

154. Rana MS, Hashem MA, Akhter S, Habibullah M, Islam MH, Riswas RC. Effect of heat stress on carcass and meat quality of indigenous sheep of Bangladesh, Bangladesh. J Anim Sci. 2014;43.

155. Bishop-Williams KE, Berke O, Pearl DL, Hand K, Kelton DF. Heat stress related dairy cow mortality during heat waves and control periods in rural Southern Ontario from 2010-2012. BMC Vet Res. 2015;11:291. doi:10.1186/s12917-015-0607-2.

156. Morignat E, Perrin J, Gay E, Vinard J, Calavas D, Hénaux V. Assessment of the impact of the 2003 and 2006 heat waves on cattle mortality in France. PLoS One. 2014;9:e93176. doi:10.1371 /journal.pone.0093176.

157. Morignat E, Gay E, Vinard J, Calavas D, Hénaux V. Quantifying the influence of ambient temperature on dairy and beef cattle mortality in France from a time-series analysis. Environ Res. 2015;140:524-34. doi:10.1016/j.envres.2015.05.001.

158. Vitali A, Felici A, Esposito S, Bernabucci U, Bertocchi L, Maresca $\mathrm{C}$, et al. The effect of heat waves on dairy cow mortality. J Dairy Sci. 2015;98:4572-9. doi:10.3168/jds.2015-9331.

159. Frank D, Reichstein M, Bahn M, Thonicke K, Frank D, Mahecha $\mathrm{MD}$, et al. Effects of climate extremes on the terrestrial carbon cycle: concepts, processes and potential future impacts. Glob Chang Biol. 2015;21:1-20. doi:10.1111/gcb.12916.

160. Niu S, Luo Y, Li D, Cao S, Xia J, Li J, et al. Plant growth and mortality under climatic extremes: an overview. Environ Exp Bot. 2014;98:13-9. doi:10.1016/j.envexpbot.2013.10.004.

161. Scholes R, J, Betts R, Bunn S, Leadley P, Nepstad D, Overpeck JT et al. Chapter 4: terrestrial and inland water systems. Clim Chang Impacts Adapt Vulnerability. 2014;271-359.

162. Teskey R, Wertin T, Bauweraerts I, Ameye M, McGuire MA, Steppe K. Responses of tree species to heat waves and extreme heat events. Plant Cell Environ. 2014;38:1699-712. doi:10.1111 /pce. 12417.

163. Allen CD, Breshears DD, McDowell NG. On underestimation of global vulnerability to tree mortality and forest die-off from hotter drought in the Anthropocene. Ecosphere. 2015;6:1-55. doi:10.1890/ES15-00203.1.

164. Anderegg WRL, Kane J, Anderegg LDL. Consequences of widespread tree mortality triggered by drought and temperature stress. Nat Clim Chang. 2013;3:30. doi:10.1038/NCLIMATE1635.

165. Filewod B, Thomas SC. Impacts of a spring heat wave on canopy processes in a northern hardwood forest. Glob Chang Biol. 2014;20:360-71. doi:10.1111/gcb.12354.

166. Matusick G, Ruthrof KX, Brouwers NC, Dell B, Hardy GSJ. Sudden forest canopy collapse corresponding with extreme drought and heat in a Mediterranean-type eucalypt forest in 
southwestern Australia. Eur J For Res. 2013;132:497-510. doi:10.1007/s 10342-013-0690-5.

167. De Boeck HJ, Bassin S, Verlinden M, Zeiter M, Hiltbrunner E. Simulated heat waves affected alpine grassland only in combination with drought. New Phytol. 2016;209(2):531-41.

168. Hoover DL, Knapp AK, Smith MD. Resistance and resilience of a grassland ecosystem to climate extremes. Ecology. 2014;95:264656. doi:10.1890/13-2186.1.

169. Qu L, Chen J, Dong G, Jiang S, Li L, Guo J, et al. Heat waves reduce ecosystem carbon sink strength in a Eurasian meadow steppe. Environ Res. 2016;144:39-48. doi:10.1016/j. envres.2015.09.004.

170. Zona D, Lipson DA, Richards JH, Phoenix GK, Liljedahl AK, Ueyama M, et al. Delayed responses of an Arctic ecosystem to an extremely dry summer: impacts on net ecosystem exchange and vegetation functioning. Biogeosci Discuss. 2013;11:5877-88. doi:10.5194/bgd-10-19189-2013.

171. Reichstein M, Bahn M, Ciais P, Frank D, Mahecha MD, Seneviratne SI, et al. Climate extremes and the carbon cycle. Nature. 2013;500:287-95. doi:10.1038/nature12350.

172. Wang X, Piao S, Ciais P, Friedlingstein P, Myneni RB, Cox P, et al. A two-fold increase of carbon cycle sensitivity to tropical temperature variations. Nature. 2014;506:212-5. doi:10.1038/nature12915.

173. Park Williams A, Allen CD, Macalady AK, Griffin D, Woodhouse CA, Meko DM, et al. Temperature as a potent driver of regional forest drought stress and tree mortality. Nat Clim Chang. 2012;3: 292-7. doi:10.1038/nclimate1693.

174. Alan Williams C. Heat and drought extremes likely to stress ecosystem productivity equally or more in a warmer, $\mathrm{CO} 2$ rich future. Environ Res Lett. 2014;9:101002. doi:10.1088/17489326/9/10/101002.

175. Law BE. Regional analysis of drought and heat impacts on forests: current and future science directions. Glob Chang Biol. 2014;20: 3595-9. doi:10.1111/gcb.12651.

176. Gasparrini A, Guo Y, Hashizume M, Lavigne E, Zanobetti A, Schwartz J, et al. Mortality risk attributable to high and low ambient temperature: a multicountry observational study. Lancet. 2015;386:369-75. doi:10.1016/S0140-6736(14)62114-0.

177. Margolis HG. Heat waves and rising temperatures: human health impacts and the determinants of vulnerability. Glob Clim Chang Public Heal. 2014;383-391. doi:10.1007/978-1-4614-8417-2.

178. Rosenthal JK, Kinney PL, Metzger KB. Intra-urban vulnerability to heat-related mortality in New York City, 1997-2006. Health Place. 2014;30:45-60. doi:10.1016/j.healthplace.2014.07.014.

179. Barreca AI. Climate change, humidity, and mortality in the United States. J Environ Econ Manag. 2012;63:19-34. doi:10.1016/j. jeem.2011.07.004.

180. Watkiss P, Hunt A. Projection of economic impacts of climate change in sectors of Europe based on bottom up analysis: human health. Clim Change. 2012;112:101-26. doi:10.1007/s10584011-0342-z.

181. Field C, Barros V, Mastrandrea M, Mach K. Climate change 2014: impacts, adaptation, and vulnerability, intergovernmental panel. Clim Chang. 2013;1-29.

182. Zwiers FW, Zhang X, Feng Y. Anthropogenic influence on long return period daily temperature extremes at regional scales. J Climate. 2011;24:881-92. doi:10.1175/2010JCLI3908.1.

183. Min SK, Zhang X, Zwiers F, Shiogama H, Tung YS, Wehner M. Multimodel detection and attribution of extreme temperature changes. J Climate. 2013;26:7430-51. doi:10.1175/JCLI-D-12-00551.1.

184. Christidis N, Stott PA, Brown SJ. The role of human activity in the recent warming of extremely warm daytime temperatures. J Climate. 2011;24:1922-30. doi:10.1175/2011JCLI4150.1.

185. Christensen JH, Boberg F. Temperature dependent climate projection deficiencies in CMIP5 models. Geophys Res Lett. 2012;39:15. doi:10.1029/2012GL053650.

186. Boberg F, Christensen JH. Overestimation of Mediterranean summer temperature projections due to model deficiencies. Nat Clim Chang. 2012;2:433-6. doi:10.1038/nclimate1454.

187. Coumou D, Rahmstorf S. A decade of weather extremes. Nat Clim Chang. 2012;2:1-6. doi:10.1038/nclimate1452.

188. Schär C. Climate extremes: the worst heat waves to come. Nat Clim Chang. 2015;1-2. doi:10.1038/nclimate2864. 